dad simultaneously complete drying of the plaster; and soivery comfortable are young children in these hammocks; that they either enjoy Ate swinging notion, or not unfrequently fall asleep. When the bats wo has firtily set fand not before, for the patient cah remain swaing for Hy teasonable 'space of time'), the whole hammock and patient are axefi down; the superflitous endstare neatly cut off with scissors, and the teetretral effect is shown in the sketchtaken from mylast patient (Frg. 3); so inter in these instances it may be kterally said, and without irreverence, they take up their bed and walk; the canvas rempant acting as an atecisory vest to the patient's'frame.

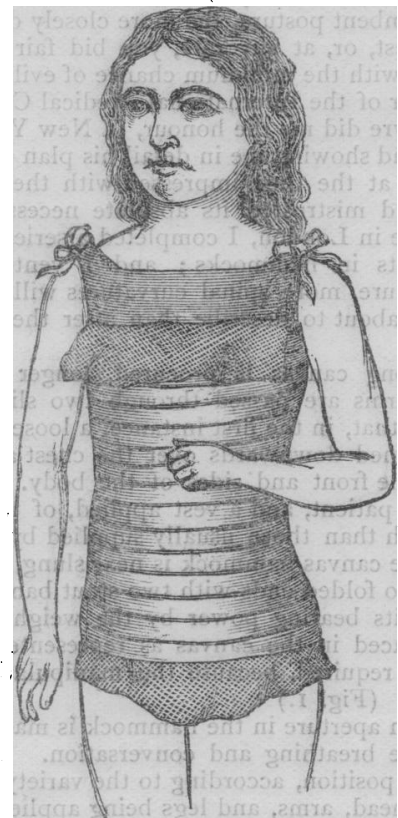

Fif: 3:-Patient in the erect posture ; the upper and lower ends. of the canvass having been neatly trimmed off.

I am ready to endorse much that has been written by Dr. Walker, Surgeon to the Peterborough Infirmary, on the utility of the recumbent posture (BRITISH MEdCAL JoukNAL, March Ist, 1879); but think that my method negatives No. 4 conclusion in his summary : "The only way in which such a jacket can be applied with the patient recumbent is by the method which I have demonstrated."

Mr. Cocking, the well-known felt manufacturer for spinal jackets, attended one of my demonstrations in the theatre of Westminster Hos: pital on May I8th, I880; he considers that this hammuck-sioperaciar may prove very convenient for the application of his faltsuppostow yet, he has only tried it in one instance. This hammock and risk to
then, in my own practice obviates ail the inconveniences and patients; secures the advantages of Sayre's method; facilitates the manual procedures of the surgeon; permits of quick and equable drying ; and necessitates no change of posture between the application of thesdupporting bandage and its final setting.

Ggherthird point is the weight of the plaster-of-Paris. I am experimonting now on felt bandages saturated with a quaickly drying solution, but will defer judgment on them until my experience is confirmed by further practical trial.

I can highly recommend a solution of plaster-of-Paris and hair intermixed. You have seen me put up many cases of talipes with this mixture; hair plays an important intertangling part, and from its elasticity and lightness, a very easy and accurately-moulded cast results. This species of felt packing will undoubtedly supplant the plaster-ofParis, on the sole argument of its specific weight. Nothing can go against the grain of a thoughtful surgeon more than to handicap an already puny patient with a heavy weight, for most of these clients with paralysed muscles can scarcely carry their own weight, much less that of even a few ounces extra.

One word, in conclusion, on the subject of portability and expense. Any country surgeon can carry hammock and bandages in tis ceat pocket, and so operate easily at the child's home instead of its being brought to the tripod. The cost of the hammock is under one shilling, and it may be extemporised out of a common sheet or a long night-shirt. I can truthfully state that, although we possess the complete tripod and apparatus at the Westminster Hospital, and have used it seldom, its joints are becom from desuetude, gtving way to the simpter, but equally practical system of hammock suspension.

\section{THE TREATMENT OF ASTHMA.}

By J. B. BERKART, M.D.,

Senior Assistant-Physician to the City of London Hospital for Diseases of the Chest, etc.

\section{II.}

CASE II.-Wm. R., a tailor, aged 66, was seen July 29, 1879, labouring under great dyspncea. He stood with his hands resting on a table, his neck stretched, his chin raised, gasping for breath, and pathetically told me that thus he had passed most of his nights for the last fourteen years, He: complained of tightness across the chest, of incessant cough, and of scanty and difficult expectoration. In short and broken sentences, he stated that he had been subject to "colds" for many years previous'to the appeardince of his asthmatic seizures, which had come upon him with an attack of bronchîtis. Treatment had hitherto been of little avail:; at times his distressing symptoms bad some what abated, soi thet he had been able to ro some work, but they had never entirely disappeared. For years he had been unable to lie down at nights; he could sleep only in a half-sitting posture. He had seldom passed a night without spending part of it on the edge of his bed, coughing.

W. R., of average height, pale, emaciated, had, as is typical in such cases, marked kyphosis. The upper costal arches were wide and prominent, the lower contracted. Respiration whs iheaving, 24; expira tion relatively prolonged. Resonance of the upper third of the lungs was deficient, and that of the middle and lower rather tympanitic. Both lungs extended to the sixth ribs. "Vesicular murmur was completely masked by sonoreus thonch, which 'were heard with inspiration and expiration over the grester part of the chest, fronit, nind back; while at the bases a) faint cooing was audible. Cough produced no change in these sounds. There was epigastric pulsation. The heart was covered. The impulse of the apex was neither seen nor felt, and the sounds, were drowned by the noise in the lungs. Pulse 78 , regular, somewhat large and'soft. The patient was with difficulty put to bed, and at 3.45 P.M. ten drops of a two per cent: " solution of pilocarpin* were injected into the left forearm. The injection, it is needless to add, was absolutely painless.

3.49 P.M. His face was flushed. Perspiration commenced at the forehead. Tears ran down the left cheek, on account of epiphora of the left side. There was no salivation. The oppression at the chest was relieved; the breathing was less noisy than before.

3.55 P.M. Pulse 84, fuller than before. Breathing was easy and noiseless. The patient coutdrecline. His body was covered with perspira. tion. There was no Rhonchi were considerably dimi-

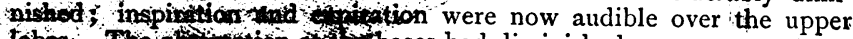
tobes: The of thotion of to bases had diminished.

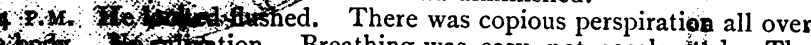
theon. 3 solion. Breathing was easy, not accelerated. The

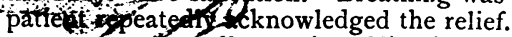

4.3 PM. Anall quantity of limpid urine passed without pain.

4. 10 P.M. Pulse 92, regular, less full, but of greater tension than before. He complained of uneasiness at the epigastrium.

4inz P.M. Heihad some hausea. A few thick, yellow, roundish sputa were raised without difficulky. "Perspiration continued.

430:P!M. Nautsea persisted. Breathing was easy. There was no cough nor expectoration. Respirations ao. The rhonchi had disappeared. Pulsei84, small, régular. IPerspiration continued.

6 P.M. Perspiration had entisely ceased. There was no vomiting. A cup of tea at five o'clock had immediately stopped sickness. Breathing was easy. The resonance of the chest was considerably impyoved ; respiratory murmur was audible all over the thorax; there nere no rhonchi. The patient felt sleepy.

July 30 th, I I A.M. The patient passed a yet night; he awoke only once, at about 2 A.M., with slight For the first time for many years, he had boen-able to lios

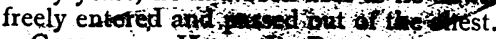

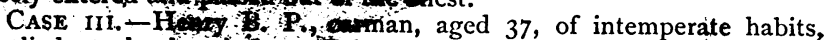
applied at the hepptai wa February 13 th, 1879 . He complained of dyspnoea, of conthy the sult expectoration-the sputa being thick and retow. clean, Thetite good. The bowels acted daily. He was ordered to

* Messrs érbyn and Co. were good enough to place a quantity of pilocarpin at 
have an ounce of compound cascarilla mixture three times a day. I saw him for the first time on February 20th, 1879, in the presence of Mr. Reilly of Globe Road. There was no improvement in the above symptoms ; on the contrary, he felt worse. The patient was suffering from great dyspnœa ; his face looked dusky, and over the malar bones quite cyanotic. Respiration was heaving, 24 ; pulse 84 , regular, soft, and small.

The patient was of middle stature, poorly nourished, and stooping, in consequence of a kyphosis. He had for sixteen years been subject to cough and nocturnal dyspnœa.

On examination, the thorax was observed to be contracted at the bases, the upper costal arches being comparatively wide and prominent. Resonance of the upper lobes was dull, but cleared up towards the bases. Sonorous rhonchi were heard all over the chest. At. 3 P.M.; ten drops of a two per cent. solution of pilocarpin were injected into the left arm. Three minutes after the injection, the face was flushed, perspiration commenced at the forehead and gradually spread over the body. The pulse became full and bounding. The patient declared himself greatly relieved. On listening to the chest, there were sonorous rhonchi at the right, and cooing at the left, upper lobes, while the bases remained obstructed. Perspiration increased, bathing the whole body. The patient was told to lie down and to rest until the effects of the drug had passed off; but he felt so much better, that he did not think it necessary to wait. However, on proceeding to dress, he became giddy. He was immediately placed upon the couch, but had soon to get up to pass urine, which was done without pain. On regaining the couch, giddiness continued. He then complained of nausea, and in a short time vomited, without effort, a great quantity of undigested food. Vomiting was repeated, and nausea and giddiness persisted. The patient moaned a great deal, and thought he was dying. He had severe pain in the left hypochondrium. The body, previously in a glow, was then covered with cold clammy perspiration. There was no pulse at the wrists, and the cardiac action was feeble; respiration was superficial and slow, and some tracheal rattling was heard. There were, in fact, all the alarming symptoms of collapse. Hawever, the injection of one drop of liquor atropiæ $(P . B$.$) changed the scene almost instantaneously. The$ pulse at the wrists returned, the cardiac action became perceptible, the breathing deeper, and the patient declared himself free from giddiness and nausea. Perspiration ceased, and he felt cold and shivering. The breathing was easy; there was no cough-nor expectoration. At 4.30 P.M., the subjective and objective symptoms were greatly improved, and the patient left the hospital. He was ordered to take an ounce of aqua menthæ piperitæ three times a day, ut aliquid fiat.

On February 27 th, he reported himself greatly improved in health. He had felt nothing but a little cold when he had returned home last week. The cough and expectoration were gone. His breathing was quite easy. He had a good appetite; almost too good, he-added, for his means. He was cheerful, dressed in his Sunday, clothes, and thought of returning to work. There was still deficient resonance and cooing at the left upper lobe; but the access of air to the rest of the lungs was unimpeded. He presented himself, as I wished him, the same evening, before Mr. Reilly, who was thus able to observe the remarkable improvement.

In May 1879, the patient returned to the hospital. He had resumed his work, but also his dissolute habits. He had again some cough ; but, in order to get rid of it as soon as possible, he requested a certificate for admission into a seaside convalescent home.

CASE IV.-J. B., tailor's cutter, aged 27, with no hereditary disposition to disease of the chest, enjoyed good health until he was seized at Glasgow, in September 1878, with nocturnal dyspnœe; wheezing, and cough. These symptoms persisted in spite of treatment when I saw him on December gth, 1878 . The patient was under-sized, very muscular, but pale, and his eyelids were baggy. He complained chiefly of the dyspnceal seizures, recurring almost every night, and accompanied by wheezing so loud as to be audible at a distance. His thorax was roomy, and his vertebral column straight and somewhat twisted to the left: There was deficient resonance in the left infraclavicular region. In both suprascapular fossæ, there was harsh respiration with dry rhonchus which, however, was conducted to them from the larynx, this being in a state of chronic inflammation. There were sonorous rhonch at both bases. The rest of the lungs, the heart, all the abdominal organs, including the kidneys, seemed healthy. The treatment was continued from December 9 th, 1878, to February 12th, 1879, but produced no decided amelioration. The dyspnœal attacks and the wheezing were relieved but returned at intervals of from two to three days. On February I 2th, several patches of broncho-pneumonia were detected in the left axillary region and at the angle of the right scapula. There were rhonchi all over. The patient was ordered an infusion of a drachm of jaborandi.
February I 3 th, I879. The pationt looked pinched. The jaborandi had produced its well-known effects. There was decided improvement of all the subjective symptoms, and the physical signs showed nothing but obstruction of the bases.

March $13^{\text {th }}$ and 19 th. The infusion of jaborandi was repeated; and since then the patient had entirely recovered. He had ever since been free from cough and from dyspnoea, and had remained hitherto: in the uninterrupted enjoyment of good health.

CASE V.- R. P., stableman, aged 52, of diminutive stature, greatly emaciated and cyanosed, had for many years been subject to congh with difficult expectoration, and to dyspnœa with nocturnal exacerbations. During the last six months, his health had been so bad that he could not do even a little light work. There were the unmistalkable signs of chronic broncho-pneumonia; and the dyspnoeal seizures were due to recurrent congestions of the lungs and to-repeated obstruction of the bronchi. He was treated from the commencement of February to the end of March, 1879, by injections of pilocarpin, six upon the whole, of which each was given at one week's interval. The effect of the pilocarpin was precisely as in the cases above mentioned; only this patient greatly suffered from salivation, owing to the cedematous condition of his buccal mucous membrane--a state he acquired by his excessive smoking of tobacco, of stramonium, and, of late, of tobacco mixed with arsenic. The local application of atropin previously to the injection of pilocarpin did not prevent salivation; nevertheless the patient was anxious to have the injections repeated, such was the relief they aftorded him. At the end of March, he had considerably improved. The cyanosis had entirely disappeared. He looked pale, but his breath was free. He could lie down at night and sleep undisturbed by cough or by dysprioea. There was also considerable im. provement in the objective signs. He was then anxious to return to his work. I saw him again in May. 1880. He had spent, he told me, a better winter than he had done for many years. He coughed at times; but his breath was much easier. All he now complained of was that he could find no work.

In all the cases above referred: to, the asthmatic paroxysms were speedily-within a few minutes-relieved by pilocarpin; and that relief was due, not merely to the suppression of the painiul perception of the dyspnoea, but to the removal, as far as practicable, of its immediate and remote causes. Moreover, the improvement lasted long after the effects of the drug had passed off, and in several instances it was almost complete. Considering the decrepitude of those patients, the unfortunate circumstances of their surroundings, and their inability of following the reparative process thus initiated, the success was all that could be expected: Klebs, it appears, has obtained equally favourable results by the same means. "In the very obstinate forms;" he writes (Allgemeine Wiener Mediz. Zeitung, No. I, 1880), "of catarrhal inflammation of the lungs proceeding from cavities, which again and again return, usually accompanied by fever, but occasionally without it, I have never seen a lasting benefit ftom the use of so-called expectorants. Here pilocarpin, one-sixth of a grain applied by, subcutaneous iniection, has rendered the best services.

A drawback to the administration of pilucarpin may be supposed to exist, in that it occasionally produces nausea, and even collapse. However, as I have: already mentioned, these unpleasant after-effects may be to a great extent obviated by precautionary measures, and it is quite possible that the smaller dose, which Klebs recommends, may be sufficient also in the cases of asthmatics, and free from every inconyenience. If, nevertheless, on that score objections were raised to its use, it needs, to refute them, but be remembered, that most of the palliative remedies of asthma-especially the so-called depressants-are attended by very disagreeable symptoms, which often persist for days after their administration; and thus it will be found that, after all, the balance-will be in favour of pilocarpin.

It is superfluous to add; that not every case called "asthma" is on that account adapted for treatment by this drug. As is well known, a great variety of affections, with nothing in common but one-and this the most conspicuous-symptom, are comprised by that name, so that the remedial measures musi necessarily differ according to the nature of the pathological state.

Again, the place of pilocarpin in therapeutics is determined by its physiological action. In all cases of chronic pneumonia, in which the nutritive disturbance proceeds from the surface of the bronchi and gradwally spreads to the stroma of the lungs, or in which it commences in the interstitial tissue and implicates the mucous membrane of the air-tubes-whethex the process terminates in atrophy or in, sclerosisthere pilocarpin, provided the state of the heart offers no contraindication, will prowe beneficial. More speedily and more safely than any other remedy, it relieves the congestion of the bronchial mucous membrane; favours the expulsion of the obstructing plug of the air-passages, 
prevents the formation of viscid mucus, diminishes the swelling of enlarged bronchial glands, and initiates a reparative process, if such be yet possible, in the infiltrated connective tissue of the lungs. Although in its effect it somewhat resembles that of a warm, or rather of a Turkish bath, it is for many reasons preferable to the latter, even in the intervals between the asthmatic seizures, when alone there can be a question of substitution. To obtain, however, the full benefit it is capable of producing, pilocarpin should be used systematically. It should be injected at intervals, commensurate to the forces and to other circumstances of the patient, until the pathological changes in the lungs are perceptibly improved.

The anatomical changes in the lungs, however, being the result of a combination of causes-local irritation and a constitutional disposition -it is obvious that even this powerful remedy would fail of its effect, unless the diseased mucous membrane of the bronchi be guarded against the injuries, to which, from ignorance of the true etiological factors of asthma, it is continually exposed; just as no dyspepsia can be cured, unless there be the needful restrictions as to diet. What those etiological factors are, I shall mention as I proceed.

\section{ON THE CHARACTERS AND MECHANISM OF THE MOST COMMON FORM OF COMMINUTED FRACTURE OF THE UPPER THIRD OF THE SHAFT OF THE.}

By EDWARD H. BENNETT, M.D., M.Ch., F.R.C.S.I., Professor of Surgery in the University of Dubliiı; Surgeon to Sir Patrick Dun's Hospital.

IN discussing this subject, I set aside the varieties of comminuted fracture of the trochanteric region of the femur, which occur as the result of the ordinary impacted extracapsular fracture of the neck of the bone, in which the fractures of the trochanters, and, if they occur, of the shaft, are direct consequences of the impaction of the neck, and are secondary to its fracture. Particular attention to this exclusion is essential ; for I shall presently demonstrate that a fracture of the neck occurs in the injury I am discussing as a secondary lesion, and with characters quite different from the common fracture, yet very easily mistakable for it in the living.

The title of my paper excludes the simple fractures "through the trochanter major" of Cooper, the intratrochanteric fracture of Hen nequin, and "the simple fracture below the trochanter minor" of Cooper. I must also exclude gunshot fractures of the upper part of the femur.

I seek to establish the propositions that the most common form of comminuted fracture of the upper third of the femur is of a definite type ; that the secondary fractures are due to a constant cause; and that a fracture involving the neck of the femur, external to the capsule, occurs as one of the secondary fractures or comminutions in the injury.

I am not acquainted with any, except the most superficial, allusions to the details of this injury in the standard treatises on fractures, nor do I know of any authority who offers any solution of the mechanical questions which its study suggests.

The first account of this fracture which $I$ have been able to find is that given in the plate and accompanying text of Sandifort's Museum Anatomicum (plate 80, f. 1, 2, 3 ; Conf. sec. 4 and 288, page 207). Here is figured, with great exactness, a comminuted fracture of the upper third of the shaft of the femur, the comminutions occurring in the upper fragment, separated by fissures, which, wide below, extend upwards as narrowing clefts to the trochanters and neck. The text con tains a description which, while it omits all mention of probable or known causes, puts the question of fracture of the neck beyond doubt. "Collum totum fuisse separatum a corpore ossis." A glance at the plate proves that the cause of comminution in this specimen was the intrusion of the lower fragment as a wedge into the upper. The pieces of the upper fragment are united around the lower, while the fissures extending to the neck and trochanters, widely separated below, become narrower as they pass to the base of the neck.

I come next, before examining a series of specimens, to the allusion of Malgaigne, in which he shows that he recognised some points in the detail of this injury; but which also shows, by its meagreness, that his acquaintance with it was most limited. He says, in describing fractures beneath the trochanters: "Quand la fracture est très-rapprochée du petit trochanter, elle est assez souvent comminutive, et combinée avec la

* Read in the Section of Surgery at the Annual Meeting of the British Medica Association in Cork, August 1879 . fracture extrà-capsulaire." The context of this passage shows that he here separates this from ordinary fractures of the neck outside the capsule; for he devotes special chapters to that injury, and here is dealing with subtrochanteric fractures of the shaft. His statement that, when the fracture is "very close to the lesser trochanter, it is liable to com. minution and to be combined with fracture of the neck", is certainly likely to mislead; for in most cases, as I shall show, the primary fracture in these injuries is rather remote from than near to the lesser trochanter. Anger, while he follows Malgaigne almost exactly in his description, furnishes, in his illustrations of subtrochanteric fractures, evidence which supports directly the views I take, both as to the essential characters of this comminuted fracture and of its relative frequency. Each of his three illustrations of comminuted subtrochanteric fracture agrees in character with the specimens I am about to submit, and with Sandifort's case, in the details of the direction of the primary fracture, in the direction of the secondary fissure, and in their extension into the cervical fracture.

I. The first of the specimens is a fracture of the upper third of the shaft of the femur, which shows distinct evidence that it had occurred some time, say a month, previously to the death of the individual from whom it was obtained. We know nothing of the life-history of the specimen. The bone has been broken most obliquely, the prime fracture extending through five inches of its length, from the middle of the anterior surface, immediately below the anterior intertrochanteric line, downward, outward, and backward to the outer side of the bone beyond the junction of the upper and centre thirds of the shaft. The lower fragment, after the prime fracture occurred, was driven into the structure of the upper, and, acting as a wedge, split it lengthwise. We can trace the secondary line of fracture upwards through the anterior face of the great trochanter to its summit, where, turning over the upper border, it passes to the depth of the digital fossa; from this it passes along and above the posterior intertrochanteric line and between the neck and lesser trochanter into the prime fracture. Thus the neck is completely detached with a small portion of the front of the shaft. But the cervical fracture has not undergone displacement. As the fracture turns over the summit of the great trochanter, a little wedge of bone is seen detached; squeezed out, as it were, by the pressure of the sides of the fracture on each other, an appearance clearly indicating that the fracturing force acted from below, as the fissures themselves indicate, for they are widest below. In this specimen I have to notice, lastly, and as most important for my purpose, that there remains a large piece of compact bone jammed in the gaping fissure, from which the secondary fractures spring. This is evidently the apex of the lower fragment, the apex of the wedge, in fact, broken off after it had split asunder the upper fragment. I have gone thus minutely into the details of this specimen, as its features are easily observed, and are of a kind which do not admit of any doubt. The remaining specimens will be seen to agree in their essential characters with it, while a reference to the plates of Sandifort and of Anger shows how closely the lines of their instances follow the same paths. This specimen belongs to Trinity College, being one of the collection of the late Professor Smith, but no record has been preserved with it.

2. The next specimen is contained in the museum of the Royal College of Surgeons, Ireland, for permission to exhibit which I am indebted to the Council of the College (Ea 569). In its details, it closely resembles that which I have just shown. The lines of its fracture are, both primary and secondary, similar. In addition, the neck has been more exactly severed from the shaft; for a fracture splits off the piece of the shaft connected to the lesser trochanter, which, in the previous specimen, retained its connection with the neck. The additional interest attaches to it, that we possess an account of the mode of occurrence of the injury. "It occurred in the infirmary of the Royal Hospital, Kirmainham, in a patient under the care of Surgeon-Major Carte. A pensioner aged 92 , while reaching across a table, broke his thigh-bone. He had all the symptoms of fracture of the neck of the bone, and in about one month he died." In this short history, given in the catalogue of the museum, the important fact is clearly stated, that the injury was the result of indirect force, and that its clinical features were such as to lead to the diagnosis of extracapsular fracture : a diagnosis correct, no doubt, in part, but erroneous in so far as it implies that the fracture of the neck was of the ordinary variety. Indeed, the author of the description in the catalogue appears to have considered it to be of the ordinary variety; for he states: "Two distinct fractures were found; one of the upper third of the femur, in which there was no attempt at union, and appeared to be subsequent to an impacted fracture of the neck of the femur." My reading of the characters of the injury is the reverse of this. I see here, as in the last specimen, a primary fracture of the shaft, with secondary fracture of the upper fragment and an extracapsular fracture of the neck, all directly result- 